\title{
Demystifying biosimilars: development, regulation and clinical use
}

\author{
Hope S Rugo*,1, Robert M Rifkin², Paul Declerck³, Angel H Bair ${ }^{4}$ \& Geraint Morgan 4 \\ ${ }^{1}$ Department of Medicine, University of California San Francisco Comprehensive Cancer Center, San Francisco, CA 94115, USA \\ ${ }^{2}$ The US Oncology Network, The Woodlands, TX 77380, USA \\ ${ }^{3}$ Department of Pharmaceutical and Pharmacological Sciences, KU Leuven, University of Leuven, Leuven, Belgium \\ ${ }^{4}$ Pfizer, Maidenhead, UK \\ *Author for correspondence: Hope.Rugo@ucsf.edu
}

Biologics are an integral component in the treatment of various diseases. However, limited patient access to these medicines remains a significant global challenge, prompting development of safe and effective biosimilars. A biosimilar is 'highly similar to a reference (originator) product, for which there are no clinically meaningful differences between the two products in terms of safety, purity and potency'. Biosimilars have the potential to offer possible benefits, including lower treatment costs, thereby increasing patient access and clinical use, which may lead to better overall outcomes. Improved understanding of biosimilars may enhance confidence and trust in these agents. As increasing numbers of biosimilars achieve regulatory approval, this overview aims to address enduring knowledge gaps regarding the development and use of biosimilars.

First draft submitted: 4 September 2018; Accepted for publication: 2 November 2018; Published online: 30 November 2018

Keywords: biosimilar • development $\bullet$ extrapolation $\bullet$ interchangeability $\bullet$ myths $\bullet$ regulatory approval

Biologics have an integral role in the treatment of cancers and autoimmune disease [1]. Patent portfolios for some biologics are nearing the end of term, leading to the development of highly similar versions of reference or 'originator' products. Since biologics are produced from genetically engineered living cells, it is not possible to create exact copies [2-4]. Therefore, highly similar versions of reference (originator) products, when approved through a stringent regulatory pathway, are referred to as 'biosimilars' $[5,6]$.

A biosimilar is defined as a biologic that is 'highly similar to a reference product, notwithstanding minor differences in clinically inactive components and for which there are no clinically meaningful differences between the two products in terms of safety, purity and potency' (Table 1) $[5,7,8]$. The availability of biosimilars is expected to provide cost savings from the use of biologic agents resulting from the abbreviated pathway to regulatory approval. As cost savings are expected to contribute to increased access, biosimilars have the potential to expand patient access to effective biologic medicines, and may provide cost savings to healthcare systems globally [9]. In addition, savings associated with biosimilars could facilitate the reallocation of resources for other aspects of patient care [10].

Small-molecule drugs are relatively simple chemicals, normally produced in a controlled manufacturing process, in predictable, fully reproducible conditions, and are unlikely to elicit any immunogenic reactions [1]. As such, generic versions of small-molecule drugs are only required to show bioequivalence to the reference product (Table 1) $[5,7,8]$. However, this approach cannot be applied to complex biologics that are produced in living cells. It is not possible to create an identical version of a biologic by an independently developed process, largely because of differences in expression systems, culture conditions, steps in purification and processing, and formulation, as well as the intrinsic heterogeneity of biologics [5].

As increasing numbers of biosimilars achieve regulatory approval and are available for use in clinical practice, it is important for the medical community to understand the underlying concepts behind the evaluation of similarity and the approval of biosimilars for use in clinical settings. Major knowledge gaps have been identified regarding biosimilars, their development and use [11]. These include understanding the approval process, the evaluation of similarity, naming of new biosimilars, issues related to safety and immunogenicity of biosimilars, the

Future Medicine 


\begin{tabular}{|c|c|c|c|c|}
\hline Term & Generic drug & $\begin{array}{l}\text { Biosimilar (or similar biotherapeutic } \\
\text { product) }\end{array}$ & Noncomparable biotherapeutics & Next-generation biologic \\
\hline Definition & $\begin{array}{l}\text { A chemically synthesized } \\
\text { medicinal product that is } \\
\text { equivalent to another in terms of } \\
\text { quality, efficacy and safety. } \\
\text { Equivalence with the reference } \\
\text { drug based on comparable } \\
\text { bioavailability }\end{array}$ & $\begin{array}{l}\text { Biologic medicine similar to an } \\
\text { authorized reference product, which } \\
\text { has undergone a rigorous regulatory } \\
\text { and scientific process, and has no } \\
\text { clinically meaningful differences in } \\
\text { terms of safety and efficacy } \\
\text { Similarity with reference product } \\
\text { demonstrated by extensive assessment } \\
\text { in terms of quality characteristics, } \\
\text { biological activity, safety and efficacy }\end{array}$ & $\begin{array}{l}\text { A biologic medicine that is intended to } \\
\text { 'copy' another biotherapeutic product; } \\
\text { has not been directly compared and } \\
\text { analyzed against an already licensed } \\
\text { reference biotherapeutic product; and } \\
\text { has not been approved via a regulatory } \\
\text { pathway that is in alignment with WHO } \\
\text { Similar Biotherapeutic Product } \\
\text { guidelines that ensure quality, safety } \\
\text { and efficacy }\end{array}$ & $\begin{array}{l}\text { A biologic that is } \\
\text { structurally altered to } \\
\text { offer improved } \\
\text { ('biobetter') or different } \\
\text { clinical performance }\end{array}$ \\
\hline
\end{tabular}

Table 2. Knowledge gaps in the understanding of biosimilarity.

\begin{tabular}{|c|c|}
\hline Knowledge gap(s) & Glossary of terms \\
\hline $\begin{array}{l}\text { Defining biologics, biosimilars } \\
\text { and biosimilarity }\end{array}$ & $\begin{array}{l}\text { - Biologics are medicinal products produced by a living organism. They are larger and more complex than small-molecule } \\
\text { drugs and typically made by genetically engineered living systems (e.g., cultured bacterial, yeast, animal or plant cells) } \\
\text { - Biosimilars are similar versions of approved biologic medicines. Biosimilarity is a regulatory term used to describe the } \\
\text { evidence and process required to demonstrate that a biologic product is 'highly similar to the reference product, } \\
\text { notwithstanding minor differences in clinically inactive components', and that 'there are no clinically meaningful differences } \\
\text { between the biosimilar and the reference product in terms of quality, safety and efficacy of the product' } \dagger\end{array}$ \\
\hline $\begin{array}{l}\text { The approval process and } \\
\text { the 'totality of evidence' to } \\
\text { evaluate biosimilars }\end{array}$ & $\begin{array}{l}\text { - 'Totality of evidence' is a concept whereby a regulatory authority will consider the totality of the data and information } \\
\text { submitted in the assessment of biosimilarity, including structural and functional characterization, nonclinical evaluation, } \\
\text { human PK and PD data, clinical immunogenicity data and comparative clinical study/studies data }\end{array}$ \\
\hline $\begin{array}{l}\text { Safety and immunogenicity of a } \\
\text { biosimilar }\end{array}$ & $\begin{array}{l}\text { - Comparative clinical study/studies are conducted to demonstrate similarity between the biosimilar and the reference } \\
\text { product, including PK, PD and immunogenicity studies followed by comparative clinical efficacy and safety (including } \\
\text { immunogenicity) } \\
\text { - Immunogenicity is also assessed post-approval for all biologics, including biosimilars }\end{array}$ \\
\hline $\begin{array}{l}\text { Rationale for extrapolation of } \\
\text { data across indications }\end{array}$ & $\begin{array}{l}\text { - Extrapolation is a concept that permits the approval of a biosimilar for use in therapeutic indications of the reference } \\
\text { product not directly evaluated in clinical studies of the biosimilar } \\
\text { - Extrapolation is based on robust scientific data and the totality of evidence }\end{array}$ \\
\hline $\begin{array}{l}\text { Defining interchangeability and } \\
\text { pharmacy-level substitution }\end{array}$ & $\begin{array}{l}\text { - According to the US FDA, an interchangeability designation may be granted for a biosimilar that is administered more } \\
\text { than once to an individual and for which it has been demonstrated that when 'the risk in terms of safety or diminished } \\
\text { efficacy of alternating or switching between use of the biologic product and the originator biologic is not greater than the } \\
\text { risk of using the product without such alternation or switch' } \\
\text { - Once a biosimilar is designated as an 'interchangeable biologic product', it may be substituted by the pharmacist, if } \\
\text { deemed appropriate and if allowed by further government regulations }\end{array}$ \\
\hline \multicolumn{2}{|c|}{$\begin{array}{l}\text { †EMA definition: 'A biosimilar is a biologic medicinal product that contains a version of the active substance of an already authorized original medicinal product (reference } \\
\text { medicinal product). For example, for an active substance that is a protein, the amino acid sequence is expected to be the same. Similarity to the reference medicinal product in } \\
\text { terms of quality characteristics, biological activity, safety and efficacy based on a comprehensive similarity exercise needs to be established.' } \\
\text { PK/PD: Pharmacokinetics/pharmacodynamics. } \\
\text { Data taken from [11]. }\end{array}$} \\
\hline
\end{tabular}

scientific rationale for extrapolation of data across clinical indications, and interchangeability (Table 2) [11]. Indeed, educational materials from the EMA [12] and the US FDA [13] are now available, and initiatives from medical societies, including the American Society of Clinical Oncology [14], are ongoing in order to increase understanding of biosimilars among patients and healthcare professionals.

The aim of this manuscript is to enhance knowledge about biosimilars and to dispel common misconceptions regarding the development, regulatory approval processes, use and the potential utility of biosimilars in clinical practice.

\section{Biosimilars: regulatory foundations \& terminology The 'totality of evidence' approach \\ Totality of evidence myths and facts are shown in Box 1.}

Since 2005, more than 40 biosimilar medicines have been approved by the EMA [15], and in the past 3 years, 12 biosimilars have been approved by the FDA [16]. A biosimilar of pegfilgrastim is the most recent addition to the biosimilar landscape, and was approved by the FDA in June 2018 [17]. This expanding biosimilar landscape highlights the well-established scientific rationale for the development and regulatory approval of biosimilars [18]. 
Box 1. Myth versus fact: 1.

Myth

- Less clinical and nonclinical evidence is required with accelerated development, resulting in less robust assessment of potential biosimilars.

Fact

- The regulatory approval of a biosimilar is granted based on the 'totality of evidence' with robust scientific and clinical data.

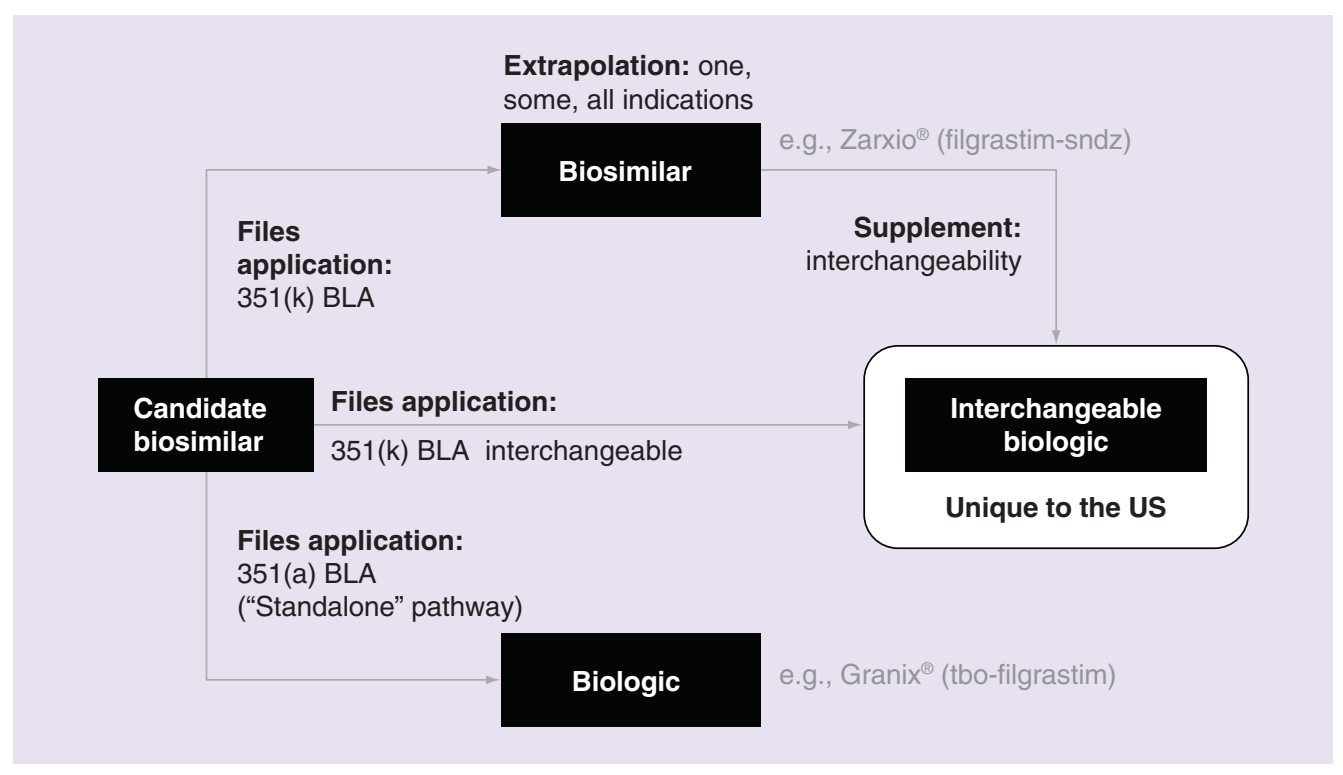

Figure 1. Approval pathways for biosimilars and interchangeable biologics in the US. As proposed by the joint BsUFA/GDUFA legislation.

BLA: Biologics license application; BsUFA/GDUFA: Biosimilar User Fee Act/Generic Drug User Fee Act.

Since by definition a biosimilar cannot be identical to the corresponding reference product, regulatory approval of a biosimilar is granted based on robust scientific data demonstrating that any differences between the potential biosimilar and the reference product are not clinically meaningful. For this reason, the development program is largely focused on analytical assessment of the structural and functional characteristics of the potential biosimilar [5]. The regulatory authorities appraise the complete data package ('totality of evidence'), including structural and functional characterization, nonclinical evaluation, assessment of clinical pharmacokinetics (PK) and immunogenicity, and comparative clinical efficacy and safety data, submitted in the Biologics License Application (Figure 1) [5]. In addition to a comprehensive data package to support the approval of a potential biosimilar, regulatory authorities require on site assessment of the manufacturing sites and processes for all biologics, including biosimilars [19]. Ultimately, biosimilars are approved by regulatory agencies (e.g., in the USA and EU) that have highly developed, well established and robust guidelines [5,7]. To date, no relevant differences between biosimilars and respective reference products have been identified by the safety monitoring system in the EU, and none of the approved biosimilars have been withdrawn as a result of safety or efficacy concerns [12].

\section{Comparability versus biosimilarity}

Comparability myths and facts are shown in Box 2.

Changes in the manufacturing process of a biologic occur over the life cycle of the product [20]. The potential impact of such changes on the clinical performance of the biologic varies. Relatively minor influences on the clinical properties of the biologic are likely from modifications to the process equipment. Major influences may arise from modifications to the purification processes, or changes to the cell line or culture media [21-23]. In addition, the characteristics of biologics, manufactured under the same conditions, can change over time. This is known as 'drift' and is influenced by several factors, including agitation, light, heat, as well as changes in the cell lines in culture [24]. 
Box 2. Myth versus fact: 2.

Myth

- Reference (originator) products that have undergone manufacturing changes are 'biosimilars' of themselves.

Facts

- Biosimilarity is a regulatory term used to describe the evaluation of a potential biosimilar against the reference product.

- A reference (originator) product undergoing planned manufacturing changes is evaluated in a comparability assessment.

\section{Box 3. Myth versus fact: 3.}

Myth

- All copies of reference (originator) products are biosimilars.

Fact

- Not all copies are biosimilars.

- Some copies of biologics exist where the regulatory pathway to their approval is unclear and/or the scientific evidence upon which approval is based is not available. These products are termed 'noncomparable biotherapeutics'.

The International Conference of Harmonization Q5E guidance documents provide the principles to evaluate whether a manufacturing process change could influence product quality, efficacy or safety and immunogenicity between batches of biologics. This is known as a comparability assessment [20]. The principles of comparability (assessment of a biologic after a manufacturing change) and biosimilarity (assessment of a potential biosimilar compared with the reference product) share scientific and regulatory principles; however, the processes differ significantly. Therefore, reference (originator) products undergoing manufacturing changes are not considered biosimilars of themselves [21,23]. Indeed, manufacturers of an approved biologic have access to all proprietary information pertaining to the biologic agent [21,22]. In contrast, the biosimilar manufacturer must create the production process through reiterative reverse engineering, using current state-of-the-art technology [25]. It is also important to note that biosimilarity is required to be demonstrated at the time of submission to the regulatory authorities only, and not at any time thereafter [21,22].

The FDA has published guidance for the assessment of those biologics for which manufacturing changes are planned. In regulatory terms, this is known as a comparability exercise [20]. The aim of a comparability exercise is to demonstrate quality, safety, efficacy and attributes of the biologic that are highly similar before and after a change in manufacturing [20]. Although all changes are evaluated on a case-by-case basis, several assessments - including batch analyses, in-process control, validation, characterization and stability testing - must be conducted to confirm that process changes do not influence critical quality attributes (CQAs), and are therefore not expected to have an adverse impact on safety or efficacy [18,20]. Although not required for all manufacturing changes, supportive nonclinical and/or clinical studies may be considered in some cases, based on risk-assessment considerations [20]. For example, the scale-up of production of Myozyme ${ }^{\circledR} /$ Lumizyme $^{\circledR}$ (alglucosidase alfa) showed substantial differences between the pre- and post-change product; as such, a new license application was required that included clinical assessment [22].

\section{Noncomparable biotherapeutics ('intended copies')}

Noncomparable biotherapeutics ('intended copies') myths and facts are shown in Box 3.

In some countries, manufacturers may claim biosimilarity with reference (originator) products [26] without evidence of extensive comparative assessments, such as those provided by the FDA, EMA and the WHO [5,7,8], and with this evidence, local regulatory approval is granted. These products (known as 'noncomparable biotherapeutics') [27] can differ in structure and functional activity, and exhibit variations in dosages or formulation that may result in clinically meaningful differences in safety and/or efficacy [28]. Therefore, noncomparable biotherapeutics should not be regarded as biosimilars of the reference product [29]. 
Box 4. Myth versus fact: 4.

Myth

- The primary structure differs between a biosimilar and the reference product.

Fact

- The primary structure of a biosimilar must be identical to the reference product, as the amino acid sequence influences the clinical properties of a biologic product.

Box 5. Myth versus fact: 5 .

\section{Myth}

- Clinical studies to evaluate potential biosimilars are designed to determine de novo efficacy and safety.

Fact

- The aim of comparative clinical studies is to confirm clinical similarity of the potential biosimilar to the reference (originator) product, not to establish clinical benefit, as this was already established for the reference product.

\section{Critical quality attributes of biosimilars}

Critical quality attributes of biosimilars myths and facts are shown in Box 4.

Although differences between the potential biosimilar and the corresponding reference product are identified, it is essential to demonstrate similarity of target quality attributes of the product (or molecule), particularly those that are implicated in the mechanism of action $(\mathrm{MoA})$ [5,7]. This is established through extensive characterization of multiple lots of the reference product, to demonstrate that the potential biosimilar is highly similar to the reference product [30,31]. Although the FDA issued draft statistical guidance (Statistical Approaches to Evaluate Analytical Similarity) regarding the evaluation of analytical similarity between a proposed biosimilar and the reference product, this guidance was recently withdrawn [32].

CQAs are key to the clinical performance of a potential biosimilar and are specific to the product [5,7], and it is particularly important that CQAs have been identified, and that similarity (potential biosimilar vs reference product) is being demonstrated based on assessment of multiple lots of the reference product for the potential biosimilar [25]. The potential biosimilar and the corresponding reference product are required to have the same primary amino acid sequence [5-8,33].

\section{Role of confirmatory clinical studies in biosimilar development}

Confirmatory clinical studies in biosimilar development myths and facts are shown in Box 5.

Regulatory authorities provide general guidance on comparative clinical trials to establish biosimilarity, and require strong scientific justification for the design of these studies [5,7]. A key part of biosimilarity assessment includes clinical PK, pharmacodynamics (PD; if relevant markers exist), efficacy (in a sensitive patient population) and safety over time, and immunogenicity of the potential biosimilar compared with the reference product. The aim of this tailored clinical program is merely to confirm the similarity of the potential biosimilar to the reference product, rather than to demonstrate clinical benefit per se, as this was established for the reference product $[5,7]$.

In contrast to clinical trials for reference (originator) biologics that are designed to establish superiority, comparative clinical efficacy and safety of a potential biosimilar are assessed using equivalence trials [5]. In the oncology setting, efficacy is often evaluated using progression-free survival (PFS) and overall survival in clinical studies. However, comparative clinical trials of potential biosimilars versus a reference product must, by necessity, employ short-term end points (e.g., overall response or pathologic complete response) to achieve the goal of accelerated development with reduced cost. These sensitive end points must correlate with long-term efficacy end points such as disease-free survival or PFS, although powering trials for response allows reasonably sized trials that confirm previously determined efficacy.

Comparative clinical trials must also include evaluation of immunogenicity, long-term safety assessment and additional secondary end points [7,30]. In addition, comparative clinical studies of potential biosimilars are based on short-term efficacy end points in a sensitive population, and are designed to demonstrate a lack of significant difference in these end points compared with the reference product. The difference in the ratio of the short-term clinical end point must fall within defined equivalence margins. Determination of equivalence margins and sample 


\section{Box 6. Myth versus fact: 6.}

Myth

- Biosimilars must have clinical data in each indication for which licensure is sought.

Fact

- Extrapolation permits approval of a biosimilar in therapeutic indications of the reference (originator) product not directly evaluated in comparative clinical studies of the biosimilar, and is based on extensive scientific data and the totality of evidence.

size are influenced by the clinical end points chosen. For example, evaluation of trastuzumab biosimilars in breast cancer has been conducted in two sensitive settings: as first-line treatment of metastatic disease using response rate as the primary end point, and as neoadjuvant therapy for early-stage breast cancer using pathologic complete response as the primary end point. Both settings compared the potential biosimilar to the reference product in combination with standard chemotherapy, allowing evaluation of safety and immunogenicity with combination therapy and extended single-agent exposure, as well as assessment of long-term end points including PFS [30].

\section{Extrapolation across clinical indications: rationale \& scientific justification}

Extrapolation across clinical indications myths and facts are shown in Box 6.

Extrapolation refers to the approval of a biosimilar for use in an indication held by the reference product, but not studied during the pivotal biosimilarity clinical trial. Indeed, extrapolation is an important part of the biosimilar approval process, and can ultimately maximize limited healthcare resources [34]. The concept of extrapolation is detailed in the FDA and EMA regulatory guidelines [5,7]. Moreover, medical societies such as the European Crohn's and Colitis Organization and European Society for Medical Oncology have mirrored the principles of extrapolation in their position statements [35,36].

Based on the extent and robustness of the evidence generated to support similarity of the potential biosimilar with the reference product, approval may be granted for the biosimilar in all indications of the approved reference product through extrapolation of overall data, including clinical data in only one indication. The type and extent of scientific justification needed to support extrapolation can differ across regulatory authorities and across indications and agents $[5,7]$.

Although extrapolation across indications reduces the need for conducting additional comparative clinical trials, further studies may be deemed necessary in certain cases (for example, to investigate differences in safety profiles aimed at resolving residual uncertainty across therapeutic indications). Indeed, the decision to grant approval based on extrapolation of data across clinical indications is based on robust scientific data and recognizes the totality of evidence, including similarity (or differences) in structural attributes, biological function, PK, PD and immunologic, safety and clinical data derived from a confirmatory trial conducted in a sensitive patient population [5]. Scientific justification for extrapolation should also consider the MoA in each indication for which licensure is sought, including the target/receptors for each relevant activity and function, receptor binding, the dose-response relationship, structure and target/receptor interactions, and the site and expression of the target/receptors [5].

Results of two comparative randomized controlled trials (PLANETAS [37] and PLANETRA [38] in patients with ankylosing spondylitis and rheumatoid arthritis, respectively) demonstrated similar PK, efficacy, safety and immunogenicity for the biosimilar CT-P13 and reference product infliximab (at all infliximab doses, as monotherapy and in combination with methotrexate). These data, combined with the extensive analytical data and the MoA, have provided support for the extrapolation of data for approval of CT-P13 in other indications [39]. Similarly, the trastuzumab biosimilar (MYL-1401O), which demonstrated equivalence with reference product trastuzumab (in combination with taxane chemotherapy as first-line treatment for metastatic HER2-positive breast cancer), was granted approval by the FDA across all approved indications of the reference product trastuzumab [40].

As well as appropriate study design, selecting a sensitive patient population in the development of biosimilars is pertinent to extrapolation. As described above, a sensitive patient population and a short-term clinical end point are required to be able to detect any possible product-related differences between the potential biosimilar and the reference product. For example, patients with CD20+ low tumor burden follicular lymphoma comprise a relatively homogeneous and sensitive population, which represents an appropriate disease model for confirming biosimilarity in a comparative clinical trial of a potential biosimilar and the reference product rituximab. As such, 
Box 7. Myth versus fact: 7.

Myth

- Immunogenicity is not extensively assessed as part of the evaluation of potential biosimilars.

Fact

- All biologics, including biosimilars, may elicit an immune response.

- Monitoring immunogenicity is an important part of the clinical program and post-approval assessment of biosimilars.

\section{Box 8. Myth versus fact: 8}

\section{Myth}

- Interchangeability does not allow pharmacists to switch between reference (originator) products and biosimilars (and vice versa) without the intervention of the prescribing physician.

Fact

- In the USA, an originator biologic may be substituted by the pharmacist with the designated 'interchangeable' biosimilar without intervention by the prescriber. This enables pharmacy-mediated substitution, where permitted by state law.

a biosimilar version of rituximab, GP-2013 (Rixathon ${ }^{\circledR}$ ), was approved in Europe for the same indications as the reference medicine, MabThera ${ }^{\circledR}$, based on therapeutic equivalence in overall response rate, $\mathrm{PK}$ and $\mathrm{PD}$, and safety profiles of GP-2013 and MabThera in patients with previously untreated follicular lymphoma [41]. Although the assessment report for GP-2013 revealed no uncertainties regarding the similarity of GP-2013 and MabThera in terms of PK and PD profiles, more patients in the MabThera arm were receiving ongoing treatment, whereas a higher number of patients treated with GP-2013 versus MabThera ended treatment in the maintenance phase, with the primary reason for discontinuation being disease progression. Moreover, studies of GP-2013 were not powered for time-to-event outcomes, with a short follow-up period. It is expected that the risk management plan will provide a greater understanding of GP-2013 through pharmacovigilance [41].

\section{Importance of immunogenicity assessment of biosimilars}

Immunogenicity myths and facts are shown in Box 7.

Treatment with biologics, including biosimilars, has the potential to elicit an immunogenic response, which may influence the clinical properties of these agents [42]. Several factors have the potential to influence immunogenicity, including disease type/status, concomitant medications, dosing, route of administration and duration of treatment. Immunogenicity may also be affected by differences in glycosylation patterns or aggregate formation [43,44]. As such, immunogenicity is assessed as part of the comparative clinical efficacy and safety trials for potential biosimilars, in line with the totality of evidence approach for the approval of biosimilars [5,7]. Thus, the presence of antidrug antibodies (ADAs) should be carefully monitored in patients receiving treatment with biologics (including biosimilars), during the clinical program, as well as during post-marketing surveillance, particularly if the incidence of the immune response is rare and unlikely to be established before licensing [10]. This is particularly important for biologics such as rituximab given that the incidence of neutralizing antibodies over time remains unclear [45].

Monitoring immunogenicity may be required as part of post-approval registries to evaluate the long-term immunogenic profile. For example, extensive post-approval programs are in place for several biosimilars, including an infliximab biosimilar [46], and biosimilars of somatropin, epoetin alfa and filgrastim [47,48]. Real-world data will facilitate the understanding of long-term safety and efficacy of the biologics in heterogeneous populations [10].

\section{Interchangeability \& switching from reference (originator) products to biosimilars}

Interchangeability myths and facts are shown in Box 8.

\section{Interchangeability}

After approval has been granted for a biosimilar, the designation of interchangeability may be granted. The FDA has issued draft guidance stating that an interchangeability designation may be granted for an approved biosimilar administered more than once to an individual when 'the risk in terms of safety or diminished efficacy of alternating 
or switching between use of the biologic product and the originator biologic is not greater than the risk of using the product without such alternation or switch'. In such cases, 'the biologic product may be substituted for the reference product without the intervention of the healthcare provider who prescribed the reference product' [49]. Indeed, this requires an additional standard for biosimilarity as defined in the statute [49].

The requirements for demonstrating interchangeability typically include a 'switching' study, in which the switching arm is expected to incorporate at least two separate exposure periods to each of the two products (i.e., at least three switches, with each switch crossing over to the alternate product) [49]. For example, an originator biologic could be replaced with a biosimilar or the biosimilar could be replaced with the originator.

However, in the EU, the designation of interchangeability is determined at a country level, and substitution policies are within the remit of the individual member states [7]. In fact, there is a large disparity between European countries with respect to substitution of biologics in general and biosimilars in particular. Moreover, medical societies across the EU have provided guidance on switching from an originator biologic to the corresponding biosimilar. For example, guidance from the British Society of Gastroenterology states that 'switching from infliximab reference product to CT-P13 (biosimilar) is safe and effective, and should be done after discussion with individual patients, with an explanation of the reason for the switch'. The decision to switch from an originator biologic to a biosimilar is based on several factors, but is largely an economic decision [50].

\section{Switching}

It is important that clinicians consider the patient population when switching from an originator biologic to a biosimilar. For example, guidance published in 2015 from the European Society for Paediatric Gastroenterology, Hepatology and Nutrition (ESPGHAN) highlighted concerns regarding extrapolation of clinical data from adults with inflammatory bowel disease (IBD) and rheumatic disease to children with IBD. As such, the ESPGHAN advised against switching to a biosimilar in pediatric patients with IBD on stable biologic treatment [51]. Enhanced communication by healthcare providers regarding decisions about switching may alleviate patient concerns and can be a useful tool when switching from originator biologics, as shown in a study in patients with rheumatic disease switching to biosimilar versions of etanercept and infliximab. The study also demonstrated that enhanced communication during switching from originator products (etanercept and infliximab) to biosimilars was associated with a lower incidence of treatment discontinuation, compared with those without adequate communication during switching [52].

It is frequently stated that current evidence suggests switching from an originator biologic to a biosimilar is not associated with differences in safety, efficacy or immunogenicity [53]. However, to date, only limited clinical data are available on switching. The major limitations of the current studies are: one switch in only one direction (generally, originator product to biosimilar, although early biosimilar to originator data are emerging [54]); small patient numbers; studies conducted in specific therapeutic indications; data are limited to only one biosimilar (i.e., CT$\mathrm{P} 13$, an infliximab biosimilar) and cannot be generalized to other biosimilars of infliximab or to biosimilars of other originator products; and lack of appropriate control groups [55-58]. In addition, it may not be possible to evaluate a therapeutic end point with switching studies, since response will have been assessed with the first treatment administered, and these studies are designed to evaluate safety and immunogenicity.

A systematic literature review was recently conducted to assess the impact of switching from originator biologics to biosimilars. The review identified no changes in the risk of immunogenicity-related safety or lower efficacy after a switch from originator biologics to biosimilars. Although each biologic and the corresponding biosimilar must be fully assessed, these findings provide reassurance to healthcare professionals and patients about the use of biosimilar medicines in clinical practice [59]. However, Pires et al. recently raised concerns over this systematic literature review, including a lack of comprehensive and systematic inclusion of relevant studies, weighting of evidence and the reporting of combined results across agents, therapeutic indications and the type of studies. Pires et al. also claimed that further studies are needed to address the impact of switching from originator biologics to biosimilars [60]. Although Cohen $e t$ al. agreed that the further research is needed to address this important issue, they highlighted that their review was unambiguous, and that it should not be assumed that switching from an originator biologic to a biosimilar is problematic [61].

A randomized, double-blind study of a biosimilar, ABP 980, and reference, trastuzumab, was conducted in patients with HER2-positive early breast cancer in the adjuvant setting. In this study, patients were randomly assigned to continue ABP 980, continue treatment with trastuzumab, or switch from trastuzumab to ABP 980 as their adjuvant therapy. This study showed that ABP 980 and trastuzumab had similar profiles in the adjuvant 
Box 9. Myth versus fact: 9.

Myth

- Biosimilars are a valid alternative option for patients with an immunogenic reaction leading to loss of response to the corresponding originator product.

Fact

- Biosimilars are expected to have similar clinical safety profiles and immunogenicity compared with the reference product. As reflected by expert opinion including from the European Crohn's and Colitis Organization IBD, Ioss of response due to immunogenicity to a biologic drug cannot be expected to be overcome with a biosimilar of the same molecule.

Box 10. Myth versus fact: 10.

\section{Myth}

- Potential cost savings are the primary factor to consider in the adoption of biosimilars.

Fact

- Biosimilars have the potential to offer reduced cost, but also should increase access to biologics, thereby improving patient outcomes.

setting [62]. Another randomized, double-blind, noninferiority study was conducted to assess the safety and efficacy of switching from infliximab reference product to CT-P13 in patients with Crohn's disease, ulcerative colitis, spondyloarthritis, rheumatoid arthritis, psoriatic arthritis and chronic plaque psoriasis (NOR-SWITCH) [63]. This study showed that switching from reference product infliximab to CT-P13 was not inferior to continued treatment with reference product infliximab over 52 weeks, according to a prespecified noninferiority margin of $15 \%$; however, the study was not powered to show noninferiority in individual diseases [63].

Switching from an originator biologic to a biosimilar (or vice versa) is a joint clinical and patient decision (that may be guided by reimbursement), made on a case-by-case basis. Several factors are taken into account in this decision-making process, including disease and patient characteristics, as well as comorbidities and the patient's consent to switch from an originator to the corresponding biosimilar version (or vice versa). Patient registries and real-world data, as well as pharmacovigilance, are key for documentation of clinical evidence in all patients who switch from treatment with originator biologics to biosimilar versions [64]. Indeed, pharmacovigilance is essential in order to identify any safety signals associated with each biologic medicine. As such, it is critical that all biologics (including biosimilars and noncomparable biotherapeutics) can be accurately traced after regulatory approval [44].

\section{Practical guidance on the use of biosimilars in clinical practice}

Practical guidance on biosimilars myths and facts are shown in Box 9.

Upon approval, biosimilars are expected to demonstrate clinical performance consistent with that of the reference product. Following adoption into clinical practice, their use, including posology and route of administration, must be consistent with that of the reference product [7]. This is reflected in the consistency between approved labels (such as the EU Summary of Product Characteristics) for reference (originator) products and biosimilars.

Biosimilars are expected to have similar clinical efficacy, safety and immunogenicity compared with the reference product, and, as reflected by the European Crohn's and Colitis Organization IBD position, it is not recommended that biosimilars are used in patients who have experienced loss of response due to an immunogenic reaction with the reference product [35]. Cross-reactivity of ADAs against the rituximab biosimilar (CT-P10) was also observed with rituximab reference product, in patients with rheumatic diseases, and would not be a suitable treatment option in ADA-positive patients previously treated with reference product rituximab [65]. Another comparative study showed that, as expected, ADAs and neutralizing antibodies against CT-P13 and infliximab reference product were crossreactive [66]. In addition, an in vitro study showed that anti-infliximab antibodies in patients with IBD recognize and functionally inhibit CT-P13 to a similar extent [67].

\section{Expanding patient access to biologic medicines}

Expanding patient access to biologic medicines myths and facts are shown in Box 10. 
Access to biologic therapies can be limited for several reasons including the cost of biologic medicines, insurance coverage, reimbursement and direct acquisition costs, as well as societal costs and out-of-pocket expenses [9]. Physicians encounter various barriers to prescribing biologic agents [68]. Many physicians consider high out-ofpocket treatment costs for patients, drug funding and reimbursement as key factors leading to canceled or delayed treatment with biologics, as well as reduced compliance, with a potential negative impact on clinical benefit [69]. Several factors may influence patients' lack of access to biologics, such as administrative challenges and financial factors, including a lack of availability of infusion facilities at medical centers, reimbursement and out-of-pocket costs, as well as insurance or public-payer coverage for biologic medicines [9].

The introduction of high-quality, safe and effective biosimilars as part of a sustainable environment provides value and possible cost savings for healthcare systems, thereby expanding patient access to these important medicines. Moreover, one analysis suggested the introduction of biosimilars in Europe has the potential to improve patient outcomes by allowing greater numbers of patients to access biologics at an earlier stage of active disease [70]. A recent analysis across countries in the EU revealed higher use of biologics, such as granulocyte-colony stimulating factors (122\%), erythropoietins (66\%), human growth hormone (41\%) and anti-TNF therapies (19\%), than in the year before the corresponding biosimilars were made available [69].

The use of biosimilars in clinical practice is largely dependent on the potential cost savings and efficiencies in healthcare and insurance infrastructure. Compared with the corresponding reference product, biosimilars can typically be $30 \%$ lower in cost in Europe, although this is highly variable [71] and reflects several factors, including biosimilar development costs, biologic manufacturing costs, entry hurdles, post-launch data requirements and the degree of competition [72]. Moreover, biosimilars may offer additional advantages such as supply-chain benefits, patient-access support networks and assistance with reimbursement administration, as well as specialist pharmacy services [73]. Such potential services and advantages can only be provided if procurement systems reflect criteria beyond price alone, and encourage frameworks that facilitate an environment for multiple biosimilar manufacturers [73,74]. In addition, post-marketing clinical studies build experience and can improve knowledge and understanding of biosimilars, and thereby increase confidence in their use [75].

Broader patient access to biosimilars will contribute to long-term cost savings, releasing resources to fund other treatments and address other healthcare priorities. A functioning and competitive biosimilar marketplace can mitigate potential problems associated with dependence on sole suppliers, including potential shortages and price volatility caused by reduced competition or availability [76].

\section{Summary}

As more biosimilars become available for use in clinical practice, healthcare professionals must understand the development process and robust regulatory assessment and approval systems in place for biosimilars and their associated data. Biosimilars are evaluated through extensive assessments using the standards provided in the regulatory guidelines. The approval of biosimilars is based on the totality of evidence, and must demonstrate similar quality, safety and efficacy between the biosimilar and the reference product.

The arrival of biosimilars has prompted healthcare professionals and the medical community to gain an understanding of the scientific foundations of biosimilarity, including the fundamental importance of analytical assessment in the development of biosimilars. As well as cost efficiencies, biosimilars have the potential to offer a wide range of benefits, including increased patient access. Indeed, the potential advantages of biosimilars over the long-term can only be realized if procurement systems account for factors beyond price alone, such as entry hurdles, data requirements and the degree of competition.

\section{Future perspective}

As increasing numbers of biosimilars gain regulatory approval and are available for use in clinical practice, healthcare professionals must understand the underlying principles of evaluating similarity and approving biosimilars. Various educational materials from the EMA and the FDA are now available, as well as initiatives from medical societies such as the American Society of Clinical Oncology, to increase understanding of biosimilars among patients and healthcare professionals. Ultimately, enhanced knowledge about biosimilars and addressing myths surrounding their development, regulatory approval process, use and potential utility in clinical practice, will contribute to increased confidence in prescribing biosimilars. 
- Access to biologic medicines can often be limited.

- The development of highly similar versions of biologics, known as biosimilars, will assist in addressing this.

- Major knowledge gaps have been identified regarding biosimilars, their development and use.

Biosimilars: regulatory foundations \& terminology

- A biosimilar is 'highly similar to a reference (originator) product and for which there are no clinically meaningful differences between the two products in terms of safety, purity and potency'.

- The regulatory approval of a biosimilar is granted based on the 'totality of evidence' with robust scientific and clinical data including analytical, preclinical, pharmacokinetic, efficacy and safety, immunogenicity, all comparison with the reference product.

Critical quality attributes of biosimilars

- Critical quality attributes are fundamental to the clinical properties of a potential biosimilar.

- A potential biosimilar and its corresponding reference product are required to have the same primary structure.

Role of confirmatory clinical studies in biosimilar development

- The goal of comparative clinical studies is to confirm similarity of the potential biosimilar and its corresponding reference product. The aim is not to determine clinical efficacy as this has already been established for the reference (originator) product.

Interchangeability \& switching from originator biologics to biosimilars

- In the USA, the originator biologic can be substituted for the biosimilar without the intervention of the healthcare provider who prescribed the reference (originator) product. This requires an additional standard to that for biosimilarity, as defined in the statute and if state laws permits.

- In the EU, the designation of interchangeability is determined at a country level.

Practical guidance on the use of biosimilars in clinical practice

- Biosimilars are expected to have similar efficacy and safety to the reference product, and, as reflected by the European Crohn's and Colitis Organization IBD position, it is not recommended that biosimilars are used in patients who have experienced loss of response due to an immunogenic reaction with the reference product.

Expanding patient access to biologic medicines

- Biosimilars may offer reduced cost, as well as the potential to expand access to biologic therapies generally, thereby improving patient outcomes.

Summary

- As increasing numbers of biosimilars become available in clinical practice, it is important that healthcare professionals have a good understanding of biosimilars, their development, regulatory approval processes and clinical utility.

\section{Acknowledgements}

The authors would like to thank PR Brown of Pfizer for his contributions to the concept of this manuscript. Medical writing support was provided by N Misra, Engage Scientific Solutions and was funded by Pfizer.

Financial \& competing interests disclosure

H Rugo received research support to the University of California for clinical trials from Genentech/Roche and Pfizer, and has received travel support to attend meetings from Amgen, Biocon, Teva and Mylan. R Rifkin participated at biosimilars advisory board meetings for Amgen, Coherus, Mylan, Pfizer, Sandoz, and is an employee (Medical Director Biosimilars) of McKession Specialty Health. P Declerck participated at advisory board meetings for AbbVie, Amgen and Hospira, and is on the speakers' bureau of AbbVie, Celltrion, Hospira, Merck Serono, and Roche. AH Bair and G Morgan are full-time employees of Pfizer. The authors have no other relevant affiliations or financial involvement with any organization or entity with a financial interest in or financial conflict with the subject matter or materials discussed in the manuscript apart from those disclosed.

No writing assistance was utilised in the writing of this manuscript.

\section{Open access}

This work is licensed under the Attribution-NonCommercial-NoDerivatives 4.0 Unported License. To view a copy of this license, visit http://creativecommons.org/licenses/by-nc-nd/4.0/ 


\section{References}

Papers of special note have been highlighted as: $\bullet$ of interest; $\bullet \bullet$ of considerable interest

1. Walsh G. Biopharmaceutical benchmarks 2010. Nat. Biotechnol. 28(9), 917-924 (2010).

2. Bui LA, Hurst S, Finch GL et al. Key considerations in the preclinical development of biosimilars. Drug Discov. Today 20(Suppl. 1), 3-15 (2015).

3. Islam R. Bioanalytical challenges of biosimilars. Bioanalysis 6(3), 349-356 (2014).

4. The European Commission. What you need to know about biosimilar medicinal products (2013). www.medicinesforeurope.com/wp-content/uploads/2016/03/biosimilars_report_en.pdf

5. US FDA. Guidance for industry: scientific considerations in demonstrating biosimilarity to a reference product (2015). www.ema.europa.eu/documents/scientific-guideline/guideline-similar-biological-medicinal-products-rev1_en.pdf

- Guidance from the US FDA on the requirements for demonstrating biosimilarity in the USA.

6. European Medicines Agency. Guideline on similar biological medicinal products (2014). www.ema.europa.eu/documents/scientific-guideline/guideline-similar-biological-medicinal-products-rev1_en.pdf

- Guidance from the EMA on the requirements for demonstrating biosimilarity in the EU.

7. European Medicines Agency. Guideline on similar biological medicinal products containing biotechnology-derived proteins as active substance: non-clinical and clinical issues (2015). www.ema.europa.eu/documents/scientific-guideline/guideline-similar-biological-medi cinal-products-containing-biotechnology-derived-proteins-active_en-2.pdf

- Guidance from the EMA on the requirements for demonstrating biosimilarity in the EU.

8. WHO. Guidelines on evaluation of monoclonal antibodies as similar biotherapeutic products (SBPs) (2016). www.who.int/biologicals/ expert_committee/mAb_SBP_GL-ECBS_review_adoption-2016.10.26-11.7post_ECBS-Clean_Version.pdf?ua=1

- Guidance from the WHO on the evaluation of monoclonal antibodies as biotherapeutic products. The principles form the foundation of the biosimilar pathways across the globe.

9. Baer WH, Maini A, Jacobs I. Barriers to the access and use of rituximab in patients with non-Hodgkin's lymphoma and chronic lymphocytic leukemia: a physician survey. Pharmaceuticals (Basel) 7(5), 530-544 (2014).

10. Weise M, Bielsky MC, De Smet K et al. Biosimilars: what clinicians should know. Blood 120(26), 5111-5117 (2012).

11. Cohen H, Beydoun D, Chien D et al. Awareness, knowledge, and perceptions of biosimilars among specialty physicians. Adv. Ther. 33(12), 2160-2172 (2017).

12. European Medicines Agency. Biosimilars in the EU: information guide for healthcare professionals (2017). www.ema.europa.eu/documents/leaflet/biosimilars-eu-information-guide-healthcare-professionals_en.pdf

13. US FDA. Biosimilars: new educational materials (2017). www.fda.gov/Drugs/DevelopmentApprovalProcess/HowDrugsareDevelopeda ndApproved/ApprovalApplications/TherapeuticBiologicApplications/Biosimilars/default.htm

14. Lyman GH, Balaban E, Diaz M et al. American Society of Clinical Oncology statement: biosimilars in oncology. J. Clin. Oncol. 36(12), 1260-1265 (2018).

15. European Medicines Agency. European Public Assessment Reports (EPAR) for Human Medicines: Biosimilars (2018). www.ema.europa.eu/en/search/search/ema_group_types/ema_medicine/search_api_aggregation_ema_medicine_types/field_ema_med_bio similar?search_api_views_fulltext=biosimilar

16. US FDA. List of licensed biological products with (1) reference product exclusivity and (2) biosimilarity or interchangeability evaluations to date (2018). www.fda.gov/downloads/Drugs/DevelopmentApprovalProcess/HowDrugsareDevelopedandApproved/ApprovalApplica tions/TherapeuticBiologicApplications/Biosimilars/UCM560162.pdf

17. US FDA. FDA approves first biosimilar to Neulasta to help reduce the risk of infection during cancer treatment (2018). www.fda.gov/NewsEvents/Newsroom/PressAnnouncements/ucm609805.htm

18. Schiestl M, Zabransky M, Sorgel F. Ten years of biosimilars in Europe: development and evolution of the regulatory pathways. Drug Des Devel Ther 11, 1509-1515 (2017).

19. BioPharma. Sandoz awaiting facility inspections before filing Humira biosimilar in US (2013). www.biopharma-reporter.com/Article/2017/01/27/Sandoz-Humira-biosimilar-US-filing-delayed-due-to-capacity-upgrade

20. International Conference on Harmonisation (ICH). Comparability of biotechnological/biological products subject to changes in their manufacturing process.

Q5E (2004). www.ich.org/fileadmin/Public_Web_Site/ICH_Products/Guidelines/Quality/Q5E/Step4/Q5E_Guideline.pdf

21. Declerck P, Farouk-Rezk M, Rudd PM. Biosimilarity versus manufacturing change: two distinct concepts. Pharm. Res. 33(2), 261-268 (2016).

22. Azevedo V, Hassett B, Fonseca JE et al. Differentiating biosimilarity and comparability in biotherapeutics. Clin. Rheumatol. 35(12), 2877-2886 (2016).

23. European Biopharmaceutical Enterprises. Biosimilarity and comparability after manufacturing changes: can a biologic become a biosimilar of itself? (2016). www.ebe-biopharma.eu/wp-content/uploads/2017/04/ebe-briefing-biosimilarity-versus-manufacturing-cha nges-public-2016-02-22-2.pdf 
24. Blackstone EA, Fuhr JP Jr. Innovation and competition: will biosimilars succeed?: The creation of an FDA approval pathway for biosimilars is complex and fraught with hazard. Yes, innovation and market competition are at stake. But so are efficacy and patient safety. Biotechnol. Healthc. 9(1), 24-27 (2012).

25. Tsuruta L, Lopes dos Santos M, Moro AM. Biosimilars advancement: moving on to the future. Biotechnol. Prog. 31(5), 1139-1149 (2015).

26. Castaneda-Hernandez G, Szekanecz Z, Mysler E et al. Biopharmaceuticals for rheumatic diseases in Latin America, Europe, Russia, and India: innovators, biosimilars, and intended copies. Joint Bone Spine 81(6), 471-477 (2014).

27. IFPMA. Non-comparable biotherapeutic products (2014). www.if pma.org/wp-content/uploads/2016/02/Non-comparable_Biotherapeutic_Products__English__02.pdf

28. Hassett B, Scheinberg M, Castaneda-Hernandez G et al. Variability of intended copies for etanercept (Enbrel(R)): data on multiple batches of seven products. MAbs 10(1), 166-176 (2018).

29. Mysler E, Pineda C, Horiuchi T et al. Clinical and regulatory perspectives on biosimilar therapies and intended copies of biologics in rheumatology. Rheumatol. Int. 36(5), 613-625 (2016).

30. Rugo HS, Linton KM, Cervi P, Rosenberg JA, Jacobs I. A clinician's guide to biosimilars in oncology. Cancer Treat. Rev. 46, 73-79 (2016).

31. Kirchhoff CF, Wang XM, Conlon HD, Anderson S, Ryan AM, Bose A. Biosimilars: key regulatory considerations and similarity assessment tools. Biotechnol. Bioeng. 114(12), 2696-2705 (2017).

32. US FDA. FDA withdraws draft guidance for industry: statistical approaches to evaluate analytical similarity (2018). www.fda.gov/Drugs/DrugSafety/ucm611398.htm

33. WHO. Guidelines on evaluation of similar biotherapeutic products (SBPs) (2009). www.who.int/biologicals/areas/biological_therapeutics/BIOTHERAPEUTICS_FOR_WEB_22APRIL2010.pdf

34. Curigliano G, O’Connor DP, Rosenberg JA, Jacobs I. Biosimilars: extrapolation for oncology. Crit. Rev. Oncol. Hematol. 104, 131-137 (2016).

35. Danese S, Gomollon F. ECCO position statement: the use of biosimilar medicines in the treatment of inflammatory bowel disease (IBD). J. Crohns Colitis 7(7), 586-589 (2013).

36. Tabernero J, Vyas M, Giuliani R et al. Biosimilars: a position paper of the European Society for Medical Oncology, with particular reference to oncology prescribers. ESMO Open 1(6), e000142 (2016).

37. Park W, Hrycaj P, Jeka $S$ et al. A randomised, double-blind, multicentre, parallel-group, prospective study comparing the pharmacokinetics, safety, and efficacy of CT-P13 and innovator infliximab in patients with ankylosing spondylitis: the PLANETAS study. Ann. Rheum. Dis. 72(10), 1605-1612 (2013).

38. Yoo DH, Racewicz A, Brzezicki J et al. A Phase III randomized study to evaluate the efficacy and safety of CT-P13 compared with reference infliximab in patients with active rheumatoid arthritis: 54-week results from the PLANETRA study. Arthritis Res. Ther. 18, 82 (2016).

39. EPAR. Assessment report: Inflectra (2013). www.ema.europa.eu/documents/assessment-report/inflectra-epar-public-assessment-report_en.pdf

40. US FDA. FDA approves first biosimilar for the treatment of certain breast and stomach cancers (2017). www.fda.gov/NewsEvents/Newsroom/PressAnnouncements/ucm587378.htm

41. EPAR. Assessment report: Rixathon (2017). www.ema.europa.eu/documents/assessment-report/rixathon-epar-public-assessment-report_en.pdf

42. Bendtzen K. Anti-TNF-alpha biotherapies: perspectives for evidence-based personalized medicine. Immunotherapy 4(11), 1167-1179 (2012).

43. Liu PM, Zou L, Sadhu C, Shen WD, Nock S. Comparative immunogenicity assessment: a critical consideration for biosimilar development. Bioanalysis 7(3), 373-381 (2015).

44. Pineda C, Castaneda Hernandez G, Jacobs IA, Alvarez DF, Carini C. Assessing the immunogenicity of biopharmaceuticals. BioDrugs 30(3), 195-206 (2016).

45. Weiner GJ. Rituximab: mechanism of action. Semin. Hematol. 47(2), 115-123 (2010).

46. EPAR. Assessment report: Remsima (2013). www.ema.europa.eu/documents/assessment-report/remsima-epar-public-assessment-report_en.pdf

47. AAPS. Approved biosimilars: case studies from Sandoz (2014). https://zerista.s3.amazonaws.com/item_files/7b59/attachments/32097/original/235.pdf

48. GaBI. Biosimilar epoetin shows good safety profile in post-authorization study (2014). www.gabionline.net/Biosimilars/Research/Biosimilar-epoetin-shows-good-safety-profile-in-post-authorization-study

49. US FDA. Considerations in demonstrating interchangeability with a reference product. Guidance for industry. Draft guidance (2017). www.fda.gov/downloads/Drugs/GuidanceComplianceRegulatoryInformation/Guidances/UCM537135.pdf

-. Guidance from the FDA on the requirements for demonstrating interchangeability of a biosimilar and its corresponding reference (originator) product. 
50. BSG. BSG Guidance on the Use of biosimilar infliximab CT-P13 in inflammatory bowel disease (2016). www.bsg.org.uk/resource/bsg-guidance-on-the-use-of-biosimilar-infliximab-ct-p13-in-ibd.html

51. de Ridder L, Waterman M, Turner $\mathrm{D}$ et al. Use of biosimilars in paediatric inflammatory bowel disease: a position statement of the ESPGHAN paediatric IBD porto group. J. Pediatr. Gastroenterol. Nutr. 61(4), 503-508 (2015).

52. Tweehuysen L, Huiskes VJB, van den Bemt BJF, van den Hoogen FHJ, den Broeder AA. FRI0200 Higher acceptance and persistence rates after biosimilar transitioning in patients with a rheumatic disease after employing an enhanced communication strategy. Ann. Rheum. Dis. 76(Suppl. 2), 557-557 (2017).

53. Uhlig T, Goll GL. Reviewing the evidence for biosimilars: key insights, lessons learned and future horizons. Rheumatology (Oxford) 56(Suppl. 4), iv49-iv62 (2017).

54. Ilias A, Szanto K, Gonczi L et al. Non-medical mandatory reversed and back and forth switch between infliximab and its biosimilar: early clinical outcomes. Presented at: 13th Congress of ECCO. Vienna, Austria, 14-17 February 2018.

55. Yoo DH, Prodanovic N, Jaworski J et al. Efficacy and safety of CT-P13 (biosimilar infliximab) in patients with rheumatoid arthritis: comparison between switching from reference infliximab to CT-P13 and continuing CT-P13 in the PLANETRA extension study. Ann. Rheum. Dis. 76(2), 355-363 (2017).

56. Park W, Yoo DH, Miranda P et al. Efficacy and safety of switching from reference infliximab to CT-P13 compared with maintenance of CT-P13 in ankylosing spondylitis: 102-week data from the PLANETAS extension study. Ann. Rheum. Dis. 76(2), 346-354 (2017).

57. Glintborg B, Sorensen IJ, Loft AG et al. A nationwide non-medical switch from originator infliximab to biosimilar CT-P13 in 802 patients with inflammatory arthritis: 1-year clinical outcomes from the DANBIO registry. Ann. Rheum. Dis. 76(8), 1426-1431 (2017).

58. Declerck P, Bakalos G, Zintzaras E, Barton B, Schreitmuller T. Monoclonal antibody biosimilars in oncology: critical appraisal of available data on switching. Clin. Ther. 40(5), 798-809.e792 (2018).

59. Cohen HP, Blauvelt A, Rifkin RM, Danese S, Gokhale SB, Woollett G. Switching reference medicines to biosimilars: a systematic literature review of clinical outcomes. Drugs 78(4), 463-478 (2018).

60. Pires A, Goyal K, Greenspan A. Comment on: 'switching reference medicines to biosimilars: a systematic literature review of clinical outcomes'. Drugs 78(8), 851-852 (2018).

61. Cohen HP, Blauvelt A, Rifkin RM, Danese S, Gokhale SB, Woollett G. Authors' reply to Pires et al.: 'Switching reference medicines to biosimilars: a systematic literature review of clinical outcomes'. Drugs 78(8), 853-855 (2018).

62. von Minckwitz G, Colleoni M, Kolberg HC et al. Efficacy and safety of ABP 980 compared with reference trastuzumab in women with HER2-positive early breast cancer (LILAC study): a randomised, double-blind, Phase 3 trial. Lancet Oncol. 19 (7), 987-998 (2018).

63. Jorgensen KK, Olsen IC, Goll GL et al. Switching from originator infliximab to biosimilar CT-P13 compared with maintained treatment with originator infliximab (NOR-SWITCH): a 52-week, randomised, double-blind, non-inferiority trial. Lancet 389(10086), 2304-2316 (2017).

64. Moots R, Azevedo V, Coindreau JL et al. Switching between reference biologics and biosimilars for the treatment of rheumatology, gastroenterology, and dermatology inflammatory conditions: considerations for the clinician. Curr. Rheumatol. Rep. 19(6), 37 (2017).

65. Coiffier B. Pharmacokinetics, efficacy and safety of the rituximab biosimilar CT-P10. Expert Rev. Clin. Pharmacol. 10(9), 923-933 (2017).

66. Reinisch W, Jahnsen J, Schreiber S et al. Evaluation of the cross-reactivity of antidrug antibodies to CT-P13 and infliximab reference product (Remicade): an analysis using immunoassays tagged with both agents. BioDrugs 31(3), 223-237 (2017).

67. Ben-Horin S, Yavzori M, Benhar I et al. Cross-immunogenicity: antibodies to infliximab in Remicade-treated patients with IBD similarly recognise the biosimilar Remsima. Gut 65(7), 1132-1138 (2016).

68. Cherny N, Sullivan R, Torode J, Saar M, Eniu A. ESMO european consortium study on the availability, out-of-pocket costs and accessibility of antineoplastic medicines in Europe. Ann. Oncol. 27(8), 1423-1443 (2016).

69. IMS. The impact of biosimilar competition in europe (2017). http://ec.europa.eu/DocsRoom/documents/23102

70. IMS. Delivering on the potential of biosimilar medicines: the role of functioning competitive markets (2016). www.iqvia.com/-/media/iqvia/pdfs/institute-reports/delivering-on-the-potential-of-biosimilar-medicines.pdf

71. Blackstone EA, Joseph PF. The economics of biosimilars. Am. Health Drug Benefits 6(8), 469-478 (2013).

72. Mestre-Ferrandiz J, Towse A, Berdud M. Biosimilars: how can payers get long-term savings? Pharmacoeconomics 34(6), 609-616 (2016).

73. Simoens S, Jacobs I, Popovian R, Isakov L, Shane LG. Assessing the value of biosimilars: a review of the role of budget impact analysis. Pharmacoeconomics 35(10), 1047-1062 (2017).

74. Dranitsaris G, Jacobs I, Kirchhoff C, Popovian R, Shane LG. Drug tendering: drug supply and shortage implications for the uptake of biosimilars. Clinicoecon. Outcomes Res. 9, 573-584 (2017).

75. Scavone C, Rafaniello C, Berrino L, Rossi F, Capuano A. Strengths, weaknesses and future challenges of biosimilars' development. an opinion on how to improve the knowledge and use of biosimilars in clinical practice. Pharmacol. Res. 126, 138-142 (2017).

76. Dranitsaris G, Dorward K, Hatzimichael E, Amir E. Clinical trial design in biosimilar drug development. Invest. New Drugs 31(2), 479-487 (2013). 